Check for updates

Cite this: RSC Adv., 2017, 7, 50449

Received 4th June 2017

Accepted 20th October 2017

DOI: 10.1039/c7ra06231a

rsc.li/rsc-advances

\section{Adsorption of sulfamethoxazole (SMZ) and ciprofloxacin (CIP) by humic acid (HA): characteristics and mechanism $\uparrow$}

\begin{abstract}
Xiaohui Liu, (DD) ab Shaoyong Lu, ${ }^{\text {b }}$ Ying Liu, ${ }^{c}$ Wei Meng ${ }^{\text {ab }}$ and Binghui Zheng ${ }^{b}$
The adsorption behaviours and mechanisms of ciprofloxacin (CIP) and sulfamethoxazole (SMZ) as adsorptives on humic acid (HA) as adsorbents were studied. The adsorption isotherms of CIP and SMZ on HA fit the Freundlich equation better, and sorption equilibrium could be attained within $12 \mathrm{~h}$. The maximum adsorption capacities of CIP and SMZ on HA were $13.64 \mathrm{mg} \mathrm{g}^{-1}$ and $7.54 \mathrm{mg} \mathrm{g}^{-1}$, both of which exhibited favourable adsorption. The kinetics results indicated that the adsorption of each antibiotic by HA followed pseudo-second-order kinetic models and that the adsorption process included the fast-adsorption stage first and the slow-adsorption stage thereafter. The adsorption efficiencies of HA to CIP were higher than those of SMZ. Compared to ionic strength, the effects of temperature and $\mathrm{pH}$ on adsorption were significant. The main adsorption mechanism of CIP and SMZ on HA could occur via hydrogen bonding. Competitive adsorption in coexistence systems of CIP and SMZ was observed on $\mathrm{HA}$, and CIP was a stronger competitor to SMZ than SMZ was to CIP.
\end{abstract}

\section{Introduction}

Antibiotics, a class of pharmaceuticals that are extensively used worldwide, ${ }^{1}$ have attracted significant concerns in recent decades due to their potential threat to ecological environments and human health. In epidemiology, antibiotics could lead to selective pressure on aquatic bacteria and induce the formation of antibiotic-resistant bacteria. ${ }^{2}$ The highest resistant rates of tetracycline, sulfamethoxazole and cefalotin sodium have reached $57 \%, 13 \%$ and $35 \%$, respectively, ${ }^{3}$ and antibiotic resistance has become a global health crisis according to the World Health Organization (WHO). However, the detection frequencies of antibiotics in aquatic environments are high, and some antibiotics have reached $\mu \mathrm{g}$ or even $\mathrm{mg}$ levels due to the extensive use of antibiotics. ${ }^{4-6}$ Antibiotics are widely used to treat or prevent human and animal diseases and promote the growth of animals in livestock and aquacultural operations. ${ }^{7,8}$ They are often partially metabolized in organisms and excreted as the parent compounds or metabolites (60-90\% of antibiotics) into the environment via urine and faeces. ${ }^{9}$

${ }^{a}$ School of Environment, Tsinghua University, Beijing 100084, China

${ }^{b}$ Dongtinghu Lake Ecological Observation and Research Station (DEORS), Chinese Research Academy of Environmental Sciences, Beijing 100012, China. E-mail: lushy2000@163.com; Tel: +86-10-84935064

${ }^{c}$ College of Geography and Environment, Shandong Normal University, Jinan 250358, PR China

† Electronic supplementary information (ESI) available. See DOI: 10.1039/c7ra06231a
The occurrence of antibiotics in the environment is affected by many factors, such as $\mathrm{pH}$, temperature and organic matter. ${ }^{10-13}$ Humic acid, which is a complex of the organic polymer class with carboxyl and hydroxyl functional groups, is widely distributed in the soil and water of rivers and lakes. ${ }^{\mathbf{1 4 , 1 5}} \mathrm{It}$ has a profound influence on the transformation of antibiotics and biological activity in the environment due to its good physiological activity and adsorption, complexation, and exchange functions of antibiotics. ${ }^{16,17}$ Guo et al. $(2015)^{18}$ revealed the adsorption characteristics of tylosin and sulfamethazine on humic acid, which were well-fitted by the Freundlich model and compartment pseudo-first-order model. Aristilde and Sposito $(2010,2013)^{\mathbf{1 9 , 2 0}}$ conducted the detailed and thorough research on the binding mechanism of CIP with humic substances (HS), which provides important insight into the intermolecular interactions leading to stable FQ antibiotic-HS complexes. The adsorption process of CIP on HS could result in structural rearrangement of $\mathrm{HS}$ and form new intermolecular $\mathrm{H}$ bonds in the CIP-HS complexes. The adsorption of antibiotics on HA could be affected by many factors, including HA structure, $\mathrm{pH}$, ionic strength and temperature. ${ }^{\mathbf{1 8 , 2 1 - 2 3}}$ In addition, the main adsorption mechanisms of antibiotics on HA include hydrophobic binding, ion exchange and hydrogen bonding. ${ }^{16,24,25}$

The pollution caused by antibiotics is especially prominent, but the adsorption mechanisms of antibiotics in environmental media are insufficient. Identifying the adsorption properties and sorption mechanisms of antibiotics with different mechanisms can effectively predict their environmental behaviour. Therefore, the adsorption behaviour and influence factors of 
CIP and SMZ on HA were studied. In addition, antibiotics in the actual environment often exist as a mixture, which could extend the residence time of antibiotics in liquids and increase their migration risk. However, most adsorption mechanisms for antibiotics on HA have analysed only a single compound, with few studies of the adsorption behaviour of the coexistence system of multiple antibiotics on HA. Therefore, the influence of coexisting substances should be considered when evaluating the migration ability of antibiotics. This paper preliminarily studies the adsorption characteristics of a coexistence system of CIP and SMZ on HA and their interacting effects. The results reveal the environmental behaviour of SMZ and CIP and provide reliable information regarding the risk level of antibiotics in actual aquatic environments.

\section{Materials and methods}

\subsection{Materials and chemicals}

Sulfamethoxazole (SMZ) and ciprofloxacin (CIP) (purity > 98\%) were purchased from Dr Ehrenstorfer GmbH (Germany), and detailed information is given in Table 1. Humic acid (HA) and calcium chloride $\left(\mathrm{CaCl}_{2}\right)$, which were guarantee reagents (GR), were obtained from Sinopharm Chemical Reagent Co. Ltd. Methanol and formic acid were of HPLC grade and obtained from Fisher Chemicals (Fair Lawn, NJ, USA). Ultrapure water was produced by a Milli-Q unit (Millipore, USA).

\subsection{Adsorption experiments of SMZ and CIP to HA}

In the batch experiment, the optimum dosage of humic acid was $4 \mathrm{~g} \mathrm{~L}^{-1}$. The influence of ionic strength was monitored by adding $\mathrm{CaCl}_{2}$ at fixed concentration of 0.001, 0.005, 0.01, 0.05, or $0.1 \mathrm{~mol} \mathrm{~L}^{-1}$. The temperature effect was quantified during the adsorption experiments at $25{ }^{\circ} \mathrm{C}(298 \mathrm{~K}), 35{ }^{\circ} \mathrm{C}(308 \mathrm{~K})$ and $45{ }^{\circ} \mathrm{C}(318 \mathrm{~K})$. The $\mathrm{pH}$ was adjusted with concentrated solutions of hydrochloric acid $(\mathrm{HCl})$ and sodium hydroxide $(\mathrm{NaOH})$, and the effect on the adsorption of CIP and SMZ on HA was studied from $\mathrm{pH} 4$ to 9 at $25{ }^{\circ} \mathrm{C}(298 \mathrm{~K})$.

In kinetic studies with concentrations of SMZ $\left(100 \mathrm{mg} \mathrm{L}^{-1}\right)$ and CIP $\left(100 \mathrm{mg} \mathrm{L}^{-1}\right)$ at $25^{\circ} \mathrm{C}(298 \mathrm{~K})$, the equilibration times were $5,10,20,40,60,120,180,360,540,720,1080,1440,2160$, and $2880 \mathrm{~min}$. The isothermal adsorption experiments for SMZ and CIP were performed at $25{ }^{\circ} \mathrm{C}(298 \mathrm{~K})$ at a concentration ranging from 10-100 $\mathrm{mg} \mathrm{L}^{-1}$. The co-adsorption experiment was performed at a fixed concentration of $100 \mathrm{mg} \mathrm{L}^{-1}$ of CIP and SMZ in mixed solution. The background solution contained $0.01 \mathrm{~mol} \mathrm{~L}^{-1} \mathrm{CaCl}_{2}$ and $200 \mathrm{mg} \mathrm{L}{ }^{-1} \mathrm{NaN}_{3}$ as a bioinhibitor. Adsorption experiments were conducted in $50 \mathrm{~mL}$ glass centrifuge tubes with a solid-liquid ratio of $1: 250$. The suspensions were kept in the dark and equilibrated for $24 \mathrm{~h}$ in a water-bath shaker at $25{ }^{\circ} \mathrm{C}(298 \mathrm{~K})$. After filtration through a $0.22 \mu \mathrm{m}$ membrane to remove particles, the final sample was transferred to a $2 \mathrm{~mL}$ amber glass bottle and stored for analysis.

\subsection{Detection of SMZ and CIP}

The concentrations of CIP and SMZ in the supernatants were quantified by an HPLC (Agilent Technologies 1200) equipped with an Athena C18-WP $(5 \mu \mathrm{m}, 4.6 \times 250 \mathrm{~mm})$ and a UV detector at $265 \mathrm{~nm}$. The column was maintained at $30^{\circ} \mathrm{C}$ during sample analysis. The mobile phase was $35: 65$ (v/v) methanol : deionized water with $0.1 \%$ formic acid at a constant flow rate of $0.8 \mathrm{~mL} \mathrm{~min}^{-1}$.

\subsection{Measuring and analysing methods of HA}

The characteristics of HA were analysed by a laser particle size analyser and specific surface area tests (BET) (ASAP2000, USA). Elemental analyses on HA before and after adsorbing CIP and SMZ were performed using a vario MACRO cube (Germany) elemental analyser to determine the $\mathrm{C}, \mathrm{H}, \mathrm{N}$ and $\mathrm{O}$ contents. The functional groups on HA before and after adsorbing CIP and SMZ were analysed using Fourier transmission infrared spectroscopy (Fourier-380 FTIR, USA). Zeta potentials of HA dissolved in deionized water were determined using a zeta potential analyser (ZetasizerNano ZS 90, Malvern, UK).

\subsection{Quality assurance and quality control}

The calibration curves $\left(0.1-100 \mathrm{mg} \mathrm{L}^{-1}\right.$ concentrations) for analyte detection presented good linearity $\left(R^{2}>0.99\right)$. Samples of CIP and SMZ solutions without solid particles were kept in the same condition as were the blank samples. The natural degradation rates of CIP and SMZ in blank samples were less than $1 \%$ and were ignored. In addition, the coefficient of variance for UPLC analysis was less than 5\% based on three measurements.

\subsection{Data analysis}

Adsorption kinetics were fitted using the first-order kinetic model, second-order kinetic model and intraparticle diffusion model:

The first-order kinetic model:

$$
\ln \left(q_{\mathrm{e}}-q_{t}\right)=\ln q_{\mathrm{e}}-k_{1} t
$$

The second-order kinetic model:

$$
\frac{t}{q_{t}}=\frac{1}{k_{2} q_{\mathrm{e}}^{2}}+\frac{t}{q_{\mathrm{e}}}
$$

Table 1 Physico-chemical properties of CIP and SMZ

\begin{tabular}{llllll}
\hline Antibiotics & CAS & Chemical formula & Molecular weight & Melting point $\left({ }^{\circ} \mathrm{C}\right)$ & log $K_{\text {ow }}$ \\
\hline CIP & $85721-33-1$ & $\mathrm{C}_{17} \mathrm{H}_{18} \mathrm{FN}_{3} \mathrm{O}_{3}$ & 331.34 & $255-257$ & 0.4 \\
SMZ & $723-46-6$ & $\mathrm{C}_{10} \mathrm{H}_{11} \mathrm{~N}_{3} \mathrm{O}_{3} \mathrm{~S}$ & 253.28 & 166
\end{tabular}


The intraparticle diffusion model:

$$
q_{t}=k_{3} t^{1 / 2}+\text { constant }
$$

where $q_{t}$ and $q_{\mathrm{e}}$ are the amounts of adsorption at time $t$ and equilibrium, respectively, $\mathrm{mg} \mathrm{g}^{-1} ; k_{1}\left(\mathrm{~h}^{-1}\right), k_{2}\left(\mathrm{~g} \mathrm{mg}^{-1} \mathrm{~min}^{-1}\right)$, $k_{3}$ ( $\left.\mathrm{mg} \mathrm{g}^{-1} \min ^{-1 / 2}\right)$ are the sorption rate constants; and $t$ is time, min.

Adsorption isotherms were fitted using the Freundlich and Langmuir models.

Freundlich model (FM):

$$
q_{\mathrm{e}}=K_{\mathrm{F}} C_{\mathrm{e}}^{1 / n}
$$

Langmuir model (LM):

$$
q_{\mathrm{e}}=\frac{K_{\mathrm{L}} q_{\mathrm{max}} C_{\mathrm{e}}}{1+K_{\mathrm{L}} C_{\mathrm{e}}}
$$

where $q_{\mathrm{e}}$ is the adsorption of CIP and SMZ, $\mathrm{mg} \mathrm{g}^{-1} C_{\mathrm{e}}$ is the adsorption equilibrium concentration of CIP and SMZ, $\mathrm{mg} \mathrm{L}^{-1}$, and $q_{\text {max }}$ is the maximum adsorption capacity, $\mathrm{mg} \mathrm{g}^{-1} K_{\mathrm{F}}$ and $n$, as the Freundlich adsorption constants, represent the adsorption capacity and adsorption intensity, respectively. $K_{\mathrm{L}}$ is the Langmuir adsorption affinity constant, $\mathrm{L} \mathrm{mg}^{-1}$.

To compare the competitive adsorption capacity of CIP and SMZ, the competitive intensity $(A, \%)$ is calculated using the following formula:

$$
A=\left(K_{\mathrm{d}}-K_{\mathrm{d}}^{\prime}\right) / K_{\mathrm{d}} \times 100 \%
$$

where $K_{\mathrm{d}}$ is the adsorption coefficient for single adsorption of main materials, $\mathrm{L} \mathrm{kg}^{-1} . K_{\mathrm{d}}^{\prime}$ is the adsorption coefficient of main materials with the existence of competitive substance, $\mathrm{L} \mathrm{kg}^{-1}$.

The effect of temperature on adsorption can be expressed using thermodynamic parameters, including $\Delta G, \Delta H$ and $\Delta S$.

Free energy changes $(\Delta G)$ are calculated using the following equation:

$$
\Delta G=-R T \ln K_{\mathrm{c}}
$$

The standard enthalpy $(\Delta H)$ and standard entropy $(\Delta S)$ is calculated using

$$
\ln K_{\mathrm{t}}=\frac{\Delta S}{R}+\frac{-\Delta H}{R T}
$$

where $R$ is the universal gas constant, $8.314 \mathrm{~J} \mathrm{~K}^{-1} \mathrm{~mol}^{-1} . T$ is the temperature in kelvin, K. $K_{\mathrm{t}}$ is the Freundlich adsorption constant at temperature $T(\mathrm{~K})$.

\section{Results and discussion}

\subsection{Adsorption kinetics of CIP and SMZ on HA}

The adsorption kinetic curves of CIP and SMZ on HA were similar (Fig. 1). The adsorption process could be divided into two stages: the rapid sorption stage ( $3 \mathrm{~h}$ ahead) and slow adsorption stage ( $3 \mathrm{~h}$ afterward), and the absorption reaction generally reached equilibrium in 12 hours. At the rapid adsorption stage, CIP and SMZ was mainly adsorbed on the

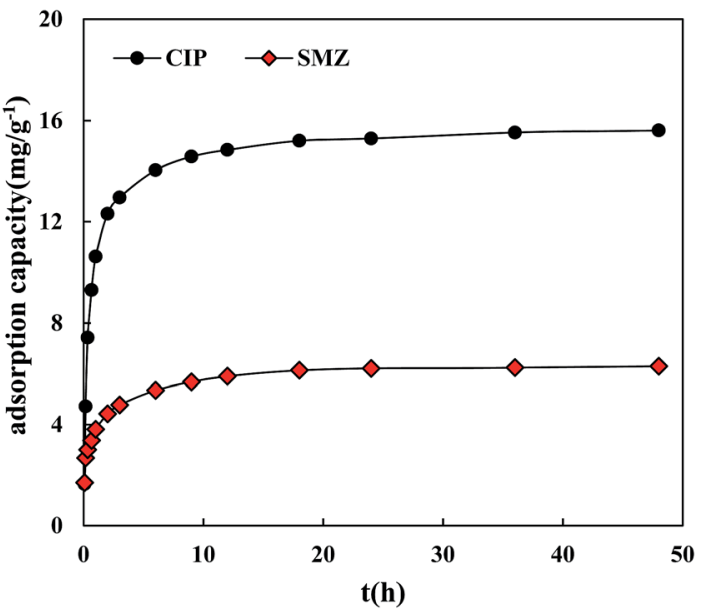

Fig. 1 Adsorption kinetics of CIP and SMZ on HA.

external surface of HA. The rapid adsorption process could be considered the movement of solute molecules along the radial direction with the least diffusion resistance, and the low sorption stage occurred gradually due to the tremendous resistance of the narrow aperture. At the slow adsorption equilibrium stage, the diffusion of CIP and SMZ was in the inner layer of HA at slow speed and was affected primarily by the properties of HA, CIP and SMZ. In addition, 24 hours was the equilibrium adsorption time to ensure the accuracy of the experimental results.

The adsorption of CIP and SMZ on HA follows a pseudosecond-order kinetic equation (CIP $-R^{2}=0.9999, \mathrm{SMZ}-$ $\left.R^{2}=0.9996\right)$ better than a pseudo-first-order kinetic equation (Table 2). It was further confirmed that the adsorption process of CIP and SMZ on HA was divided into a rapid sorption stage and slow adsorption stage, indicating that adsorption became involved in chemisorption. The adsorption rate of $1.71 \mathrm{~g}$ $\mathrm{mg}^{-1} \mathrm{~min}^{-1}$ for CIP was greater than the $1.46 \mathrm{~g} \mathrm{mg}^{-1} \mathrm{~min}^{-1}$ rate for SMZ, indicating that the adsorption activation of HA to CIP was higher in SMZ and was related to the structural properties of CIP, SMZ and HA.

To identify the diffusion mechanism of the process of adsorption CIP and SMZ on HA, the intraparticle diffusion model was used to determine whether intraparticle diffusion was the controlling factor for adsorption rate.

At the rapid adsorption stage, the adsorption process of CIP and SMZ on HA was in accordance with the intraparticle diffusion equation with good fit $\left(R^{2}>0.9\right)$ (Table 2), indicating that the adsorption rate was controlled mainly by intra-particle diffusion at the rapid adsorption stage. The whole adsorption process of SMZ on HA was not fitted by an intraparticle diffusion model, contrary to that of CIP. This result indicated that the adsorption rate was controlled by membrane diffusion and surface adsorption, in addition to intraparticle diffusion, for SMZ on HA and that the adsorption rate was controlled mainly by intraparticle diffusion for CIP on HA. The intraparticle diffusion equation did not pass through the origin for CIP, which indicated that intraparticle diffusion was the main controlling factor but was not the only one. In addition, this 
Table 2 Fitting parameters of adsorption kinetics model of CIP and SMZ on HA

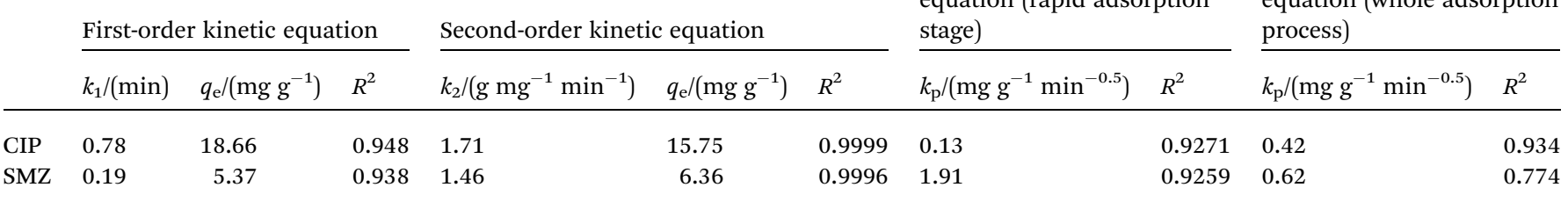

phenomenon further revealed that the adsorption capacity of CIP on HA was greater than for SMZ.

\subsection{Adsorption isotherms studies}

Fig. 2 illustrates the adsorption isotherms of CIP and SMZ on HA at $25{ }^{\circ} \mathrm{C}(298 \mathrm{~K})$. The adsorption capacity of CIP on HA was significantly higher than that for SMZ. The adsorption capacity of CIP on HA increased linearly with increasing equilibrium concentration, and the slope of the curve decreased slightly when the equilibrium concentration was above $26.84 \mathrm{mg} \mathrm{L}^{-1}$. The adsorption capacity of SMZ on HA changed slowly, and the dependence of adsorption on equilibrium concentration was small. In general, the adsorption capacity increased rapidly at low equilibrium concentrations but then flattened gradually until saturation.

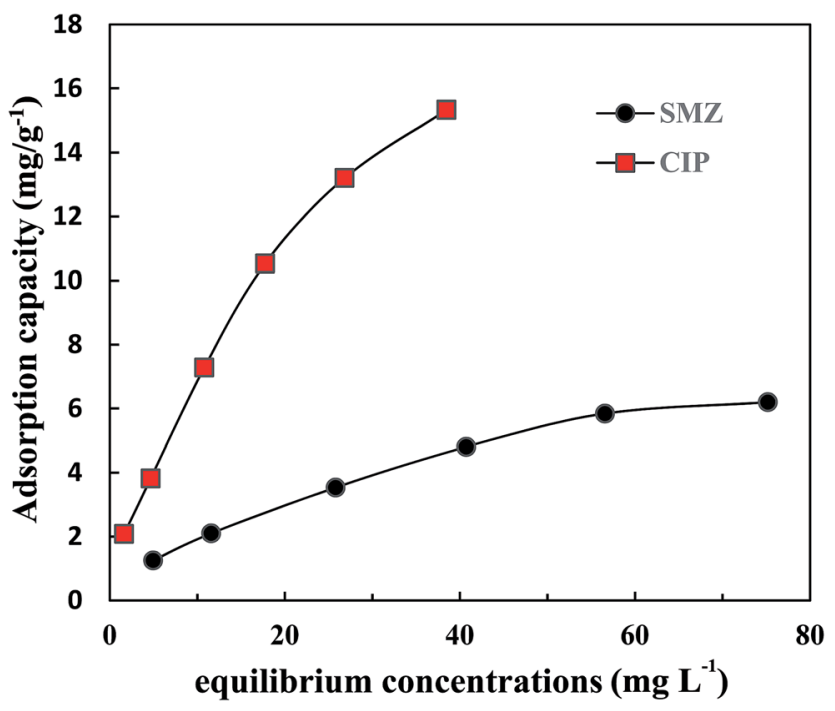

Fig. 2 Adsorption isotherms of CIP and SMZ on HA.
The adsorption isotherms of CIP and SMZ on HA were fitted by the Langmuir equation and Freundlich equation, respectively, and the results are shown in Table 3 . The correlation coefficients (CIP $-R^{2}=0.995$, SMZ $\left.-R^{2}=0.995\right)$ demonstrate that the Freundlich model was more suitable than the Langmuir model, with adsorption constants $\left(K_{\mathrm{F}}\right)$ of $1.4808\left(\mathrm{mg} \mathrm{g}^{-1}\right)\left(\mathrm{L} \mathrm{mg}^{-1}\right)^{1 / n}$ for CIP and $0.4749\left(\mathrm{mg} \mathrm{g}^{-1}\right)\left(\mathrm{L} \mathrm{mg}^{-1}\right)^{1 / n}$ for SMZ. The maximum adsorption capacity of CIP and SMZ on HA was $13.64 \mathrm{mg} \mathrm{g}^{-1}$ and $7.54 \mathrm{mg} \mathrm{g}^{-1}$. The constant $n$ obtained by Freundlich equations was 1.52 and 1.63, respectively, which reflected the favourable adsorption of CIP and SMZ on HA. In addition, the adsorption strength value $(1 / n)$ of CIP and SMZ on HA was below 1 , indicating that the adsorption isotherms of CIP and SMZ were Sshaped at $25{ }^{\circ} \mathrm{C}(298 \mathrm{~K})$ and that the proportion of antibiotic adsorption increased with increasing antibiotic concentration in a specific concentration range.

\subsection{Co-adsorption of sulfamethoxazole and ciprofloxacin on HA}

In the actual environment, the coexistence of multiple antibiotics is a common phenomenon. ${ }^{26}$ The interactions between antibiotics will change their environmental behaviours and risks. ${ }^{27-29}$ Most studies of co-adsorption focused on apparent adsorption phenomena; for example, the adsorption rate of main pollutants decreases due to competitive adsorption, contrary to synergistic adsorption. An isotherm comparison of a single adsorption system of CIP or SMZ and co-adsorption system of CIP and SMZ is shown in Fig. 3 and 4. The co-adsorption of CIP and SMZ on HA was well fitted by the Freundlich equation model (Table 4). As seen from Fig. 3 and 4, the adsorption of CIP and SMZ on HA was inhibited to some extent in the coexistence system, indicating competitive adsorption.

The competitive strength of CIP $(A=40.98 \%)$ to SMZ was 1.63 times that of SMZ to CIP $(A=25.08 \%)$, and the adsorption of CIP in the single adsorption system was also significantly higher than for SMZ, which indicated that the hydrophobic and

Table 3 Parameters of adsorption isotherm of CIP and SMZ on HA

\begin{tabular}{|c|c|c|c|c|c|c|c|}
\hline SMZ & 7.54 & 0.039 & 0.26 & 0.987 & 0.47 & 0.61 & 0.995 \\
\hline
\end{tabular}




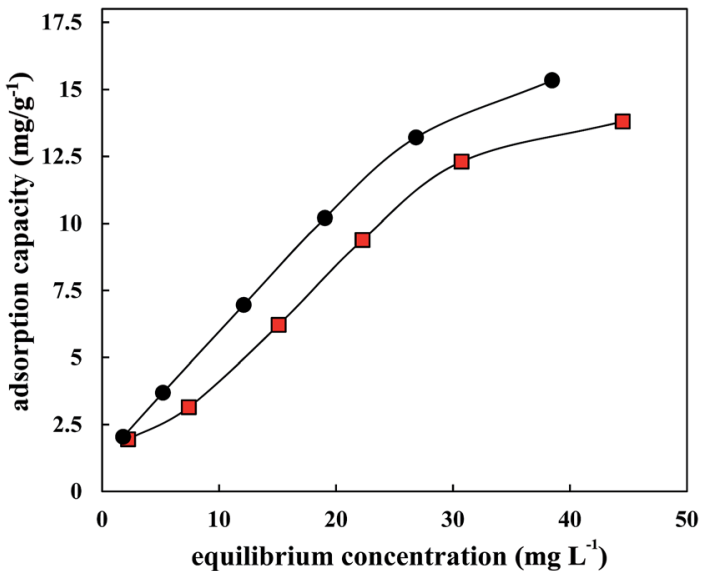

Fig. 3 Adsorption of CIP with the absence (O) and presence ( $\square$ ) of SMZ on HA.

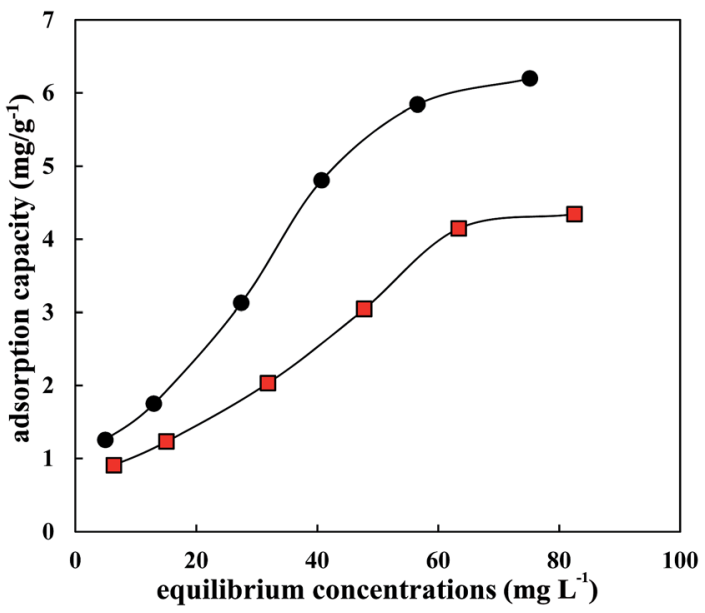

Fig. 4 Adsorption of SMZ with the absence $(O)$ and presence $(\square)$ of CIP on HA.

hydrogen bond interactions could be the main cause of the higher adsorption of CIP. In addition, the constant $n$ of CIP and $\mathrm{SMZ}$ in the coexistence adsorption system was higher than that in the single adsorption system; the main cause was that adsorption nonlinearity was reduced by competitive adsorption and the high energy sites of the main material were occupied by competing substances.

\subsection{Effects of ionic strength, temperature and $\mathrm{pH}$ on SMZ and CIP adsorption}

3.4.1 Effect of ionic strength. The adsorption of CIP and SMZ on HA could be inhibited by $\mathrm{Ca}^{2+}$, similar to previous

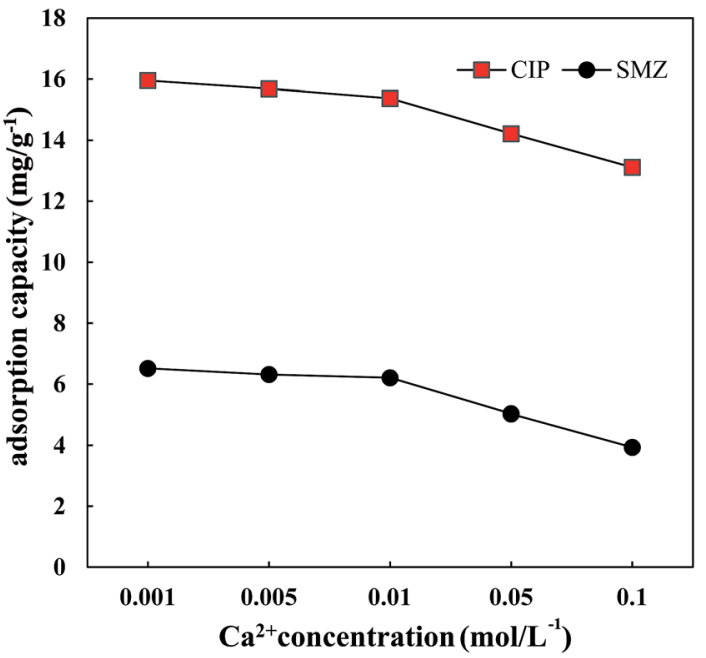

Fig. 5 Adsorption of $\mathrm{CIP}$ and $\mathrm{SMZ}$ on $\mathrm{HA}$ at different $\mathrm{Ca}^{2+}$ concentration.

research on the effect of ionic strength on adsorption, ${ }^{\mathbf{3 0 , 3 1}}$ suggesting surface complexation among CIP, SMZ and HA and a weak dependence on ionic strength (Fig. 5) which was related to the type of HA according to the findings of Aristilde and Sposito (2013). ${ }^{19}$ The adsorption constant $K_{\mathrm{d}}$ of CIP and SMZ on HA decreased gradually with an increasing $\mathrm{Ca}^{2+}$ concentration (Table 5). The negative effect of ionic strength on adsorption CIP on HA was higher than that for SMZ but not significant. When the concentration of $\mathrm{Ca}^{2+}$ was less than $0.1 \mathrm{~mol} \mathrm{~L}^{-1}$, ionic strength had little effect on the adsorption of CIP and SMZ on HA. However, the adsorption properties of HA to CIP and SMZ decreased linearly when the concentration of $\mathrm{Ca}^{2+}$ was above $0.1 \mathrm{~mol} \mathrm{~L}^{-1}$, and the degree of negative influence slightly increased compared to the concentration of $\mathrm{Ca}^{2+}$ below $0.1 \mathrm{~mol} \mathrm{~L}^{-1} \cdot \mathrm{Ca}^{2+}$ in solution can produce the $(\mathrm{CaCl})^{+}$form $^{32}$ adsorbed on the surface of HA, which can compete for exchange sites with CIP and SMZ.

In addition, $\mathrm{HA}$ is an organic macromolecule, so an increase in ionic strength could cause shrinkage and a decrease in HA pore size, leading to a decrease in the total number of adsorption sites. Electrostatic interactions between adsorbents and adsorbates decreased, whereas hydrophobic interactions increased. ${ }^{33-35}$ Therefore, a higher ionic strength was not conducive to the adsorption of CIP and SMZ on HA.

3.4.2 Effects of temperature. The adsorption process was strongly dependent on temperature. The adsorption isotherms of CIP and SMZ on HA at different temperatures are shown in Fig. 6 and 7. The adsorption of CIP and SMZ on HA was well

Table 4 Parameters of co-adsorption isotherm of CIP and SMZ on HA

\begin{tabular}{|c|c|c|c|c|c|c|}
\hline & \multicolumn{3}{|c|}{ Langmuir model } & \multicolumn{3}{|l|}{ Freundlich model } \\
\hline & $q_{\max }\left(\mathrm{mg} \mathrm{g}^{-1}\right)$ & $K_{\mathrm{L}}\left(\mathrm{L} \mathrm{mg}^{-1}\right)$ & $R^{2}$ & $K_{\mathrm{F}}\left(\mathrm{mg} \mathrm{g}^{-1}\right)\left(\mathrm{L} \mathrm{mg}^{-1}\right)^{1 / n}$ & $n$ & $R^{2}$ \\
\hline SMZ & 4.05 & 0.059 & 0.882 & 0.36 & 1.780 & 0.967 \\
\hline
\end{tabular}


Table 5 Adsorption constant $K_{\mathrm{d}}$ of $\mathrm{CIP}$ and SMZ on HA at different $\mathrm{Ca}^{2+}$ concentration $^{a}$

$\mathrm{Ca}^{2+}$ concentration Adsorption constant $K_{\mathrm{d}} \quad$ Adsorption constant $K_{\mathrm{d}}$ $\left(\mathrm{mol} \mathrm{L}^{-1}\right) \quad$ of CIP on HA $\left(\mathrm{L} \mathrm{kg}^{-1}\right)$ of SMZ on HA $\left(\mathrm{L} \mathrm{kg}^{-1}\right)$

\begin{tabular}{lll}
\hline 0.001 & 445.31 & 88.33 \\
0.005 & 421.70 & 84.64 \\
0.01 & 400.34 & 82.73 \\
0.05 & 329.93 & 62.98 \\
0.1 & 277.17 & 46.73
\end{tabular}

${ }^{a}$ The adsorption constant $K_{\mathrm{d}}$ is the ratio of adsorption capacity of CIP or SMZ on a unit mass of HA and equilibrium concentration of CIP and SMZ in solution.

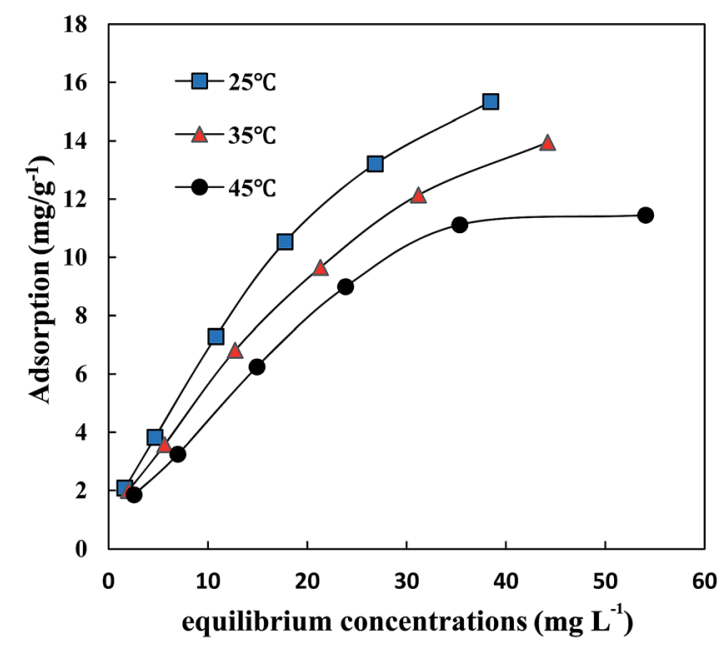

Fig. 6 Adsorption of CIP on HA at different temperatures.

fitted by the Freundlich equation model at $25{ }^{\circ} \mathrm{C}(298 \mathrm{~K}), 35{ }^{\circ} \mathrm{C}$ $(308 \mathrm{~K})$ and $45{ }^{\circ} \mathrm{C}(318 \mathrm{~K})$. The effects of temperature on the adsorption of CIP and SMZ on HA were significant. The parameter $K_{\mathrm{F}}$ in the equation can be used to evaluate the

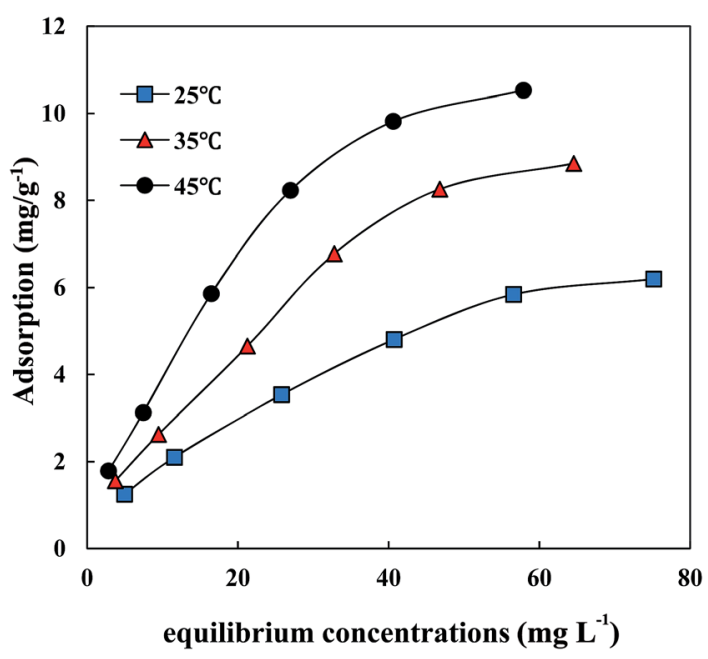

Fig. 7 Adsorption of SMZ on HA at different temperatures. adsorption properties. The parameter $K_{\mathrm{F}}$ of CIP at $298 \mathrm{~K}$ was 1.19 and 1.47 times those observed at $308 \mathrm{~K}$ and $318 \mathrm{~K}$, respectively (Table 6), which indicated that a low temperature favoured the adsorption of CIP on HA, similar to most adsorption experiments. ${ }^{36-39}$ However, the adsorption capacity of SMZ on HA increased with increasing temperature. The parameter $K_{\mathrm{F}}$ of SMZ in $318 \mathrm{~K}$ was 1.99 and 1.46 times than for $298 \mathrm{~K}$ and $308 \mathrm{~K}$, respectively, indicating that the adsorption capacity of HA to CIP significantly increased and that the high temperature was favourable to adsorption. The increase in temperature can promote the diffusion of SMZ molecules and decrease the solution viscosity, which promoted SMZ molecules passing through the outer boundary of the adsorbent to enter the internal pores. ${ }^{25}$ This was similar to the adsorption of sulfamethazine on HA. ${ }^{18}$ In addition, the effect of temperature on the adsorption of SMZ on HA was greater than for CIP. Considering the constant $n$ to have a nonlinear degree, the solution with higher concentration had lower sorption nonlinearity for SMZ, and the site energy distribution of SMZ on HA became more uniform.

Adsorption thermodynamic parameters for CIP and SMZ on HA are shown in Table 7. The free energies $(\Delta G)$ of CIP and SMZ were both below zero, suggesting that the adsorption reaction was spontaneous. The absolute value of free energy $(\Delta G)$ was below $40 \mathrm{kl} \mathrm{mol}^{-1}$, indicating that the adsorption of CIP and SMZ on HA was mainly physical, followed by chemical adsorption. ${ }^{\mathbf{4 0}}$ The thermodynamic standard enthalpy change $\Delta H$ of SMZ was greater than zero, in contrast to CIP, which indicated that the adsorption of SMZ on HA was an endothermic reaction, with an exothermic reaction of adsorption of CIP on HA, proving that a high temperature was favourable for the adsorption of SMZ on HA but that a low temperature was favourable for the adsorption of CIP. In addition, the standard entropy $(\Delta S)$ of CIP and SMZ was greater than zero with a decline in system orderliness and an improvement in energy, which indicated that the functional groups of HA changed during adsorption to CIP and SMZ; this was confirmed by the infrared spectra of HA and coating with CIP or SMZ. In addition, this result indicated that CIP and SMZ could be fixed by HA in aquatic environments to somewhat diminish environmental pollution and ecological risk. However, the adsorption mechanism of CIP and SMZ on HA depended on physical adsorption, which is reversible. Therefore, the secondary release of CIP and SMZ on HA was due to environmental changes, which should be further investigated.

3.4.3 Effect of $\mathbf{~ p H}$. The $\mathrm{pH}$ value has a great impact on the adsorption of antibiotics. Antibiotics exist as ionic organic pollutants ${ }^{41,42}$ could be affected by solution $\mathrm{pH}$. In addition, the form and structure of HA could be affected by $\mathrm{pH}$. When the $\mathrm{pH}$ value is over a certain range, the functional groups, such as hydroxyl and carboxyl, will be hydrolyzed and affect the surface charge on HA.

The adsorption capacity of CIP on HA first increased and then decreased with a variation in the $\mathrm{pH}$ of the aqueous solution (Fig. 8). When the $\mathrm{pH}$ was 5, the adsorption effect of CIP on HA was best, with an adsorption capacity of $16.76 \mathrm{mg} \mathrm{g}^{-1}$, similar to the adsorption of CIP on river sediments ${ }^{43}$ and ustic cambosols. ${ }^{44}$ 
Table 6 Parameters of adsorption isotherm of CIP and SMZ on HA at different temperature

\begin{tabular}{|c|c|c|c|c|c|c|c|}
\hline & Temperature & \multicolumn{3}{|c|}{ Langmuir model } & \multicolumn{3}{|l|}{ Freundlich model } \\
\hline & $35{ }^{\circ} \mathrm{C}(308 \mathrm{~K})$ & 14.45 & 0.077 & 0.974 & 1.24 & 0.65 & 0.995 \\
\hline & $45^{\circ} \mathrm{C}(318 \mathrm{~K})$ & 13.64 & 0.059 & 0.974 & 1.01 & 0.65 & 0.977 \\
\hline SMZ & $25^{\circ} \mathrm{C}(298 \mathrm{~K})$ & 7.54 & 0.039 & 0.987 & 0.47 & 0.61 & 0.995 \\
\hline
\end{tabular}

Table 7 Adsorption thermodynamic parameters of CIP and SMZ on $\mathrm{HA}$

\begin{tabular}{|c|c|c|c|c|c|c|}
\hline \multirow[b]{2}{*}{ Temperature } & \multicolumn{2}{|c|}{$\Delta G /\left(\mathrm{kJ} \mathrm{mol}^{-1}\right)$} & \multicolumn{2}{|c|}{$\Delta H /\left(\mathrm{kJ} \mathrm{mol}^{-1}\right)$} & \multicolumn{2}{|c|}{$\begin{array}{l}\Delta S / \\
\left(\mathrm{J} \mathrm{K}^{-1} \mathrm{~mol}^{-1}\right)\end{array}$} \\
\hline & CIP & SMZ & CIP & SMZ & CIP & SMZ \\
\hline $25{ }^{\circ} \mathrm{C}(298 \mathrm{~K})$ & -18.09 & -15.27 & -15.05 & 27.23 & 10.25 & 142.51 \\
\hline $35^{\circ} \mathrm{C}(308 \mathrm{~K})$ & -18.24 & -16.59 & & & & \\
\hline $45^{\circ} \mathrm{C}(318 \mathrm{~K})$ & -18.29 & -18.12 & & & & \\
\hline
\end{tabular}

The form of CIP can change with pH. The cationic form of CIP was predominant in equilibrium solutions due to the binding of amine groups on CIP and $\mathrm{H}^{+}$(ref. 45) (Fig. S1†), and HA had large carboxyl, hydroxyl and sulfo functional group with positive charges under acidic conditions. There is some classical repulsive force between CIP and humic acid, but CIP can be adsorbed on HA via ion exchange and hydrogen bonds. With an increase in the alkalinity of the aqueous solution, the zwitterion and anion of CIP were predominant due to the binding of amine groups on CIP and $\mathrm{OH}^{-}$, and the adsorption capacity of HA to CIP was weakened. The active functional groups of HA (carboxyl and phenolic hydroxyl groups) would transform from molecule to anion, so CIP and HA were mutually exclusive, and the configuration extension and hydrogen bond between HA and ciprofloxacin obviously decreased. Therefore, the surface physical

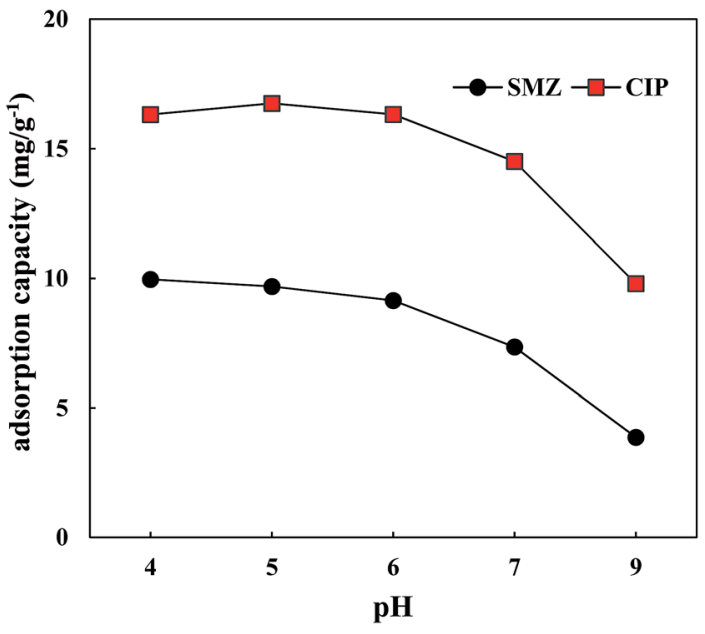

Fig. 8 Adsorption of CIP and SMZ on HA at different $\mathrm{pH}$. adsorption due to electrostatic attraction was weakened, which could reduce the adsorption of CIP on HA.

The adsorption capacity of SMZ on HA decreased nonlinearly with the increase in solution $\mathrm{pH}$. When the solution $\mathrm{pH}$ was less than 1.6, the cationic form of CIP was predominant in equilibrium solutions (Fig. $\mathrm{S} 2 \dagger$ ), and SMZ could be adsorbed on HA by the ion exchange and hydrogen bonds. When the solution pH was between 1.6 and 5.7, the neutral molecules and cationic form of SMZ were predominant in equilibrium solutions, which the neutral molecules were higher. ${ }^{46}$ At this time, the ion exchange was significantly weakened. In addition, the adsorption capacity of SMZ on HA was small and exhibited a minor difference when the $\mathrm{pH}$ ranged from 4 to 6 . The change in the adsorption capacity of SMZ on HA was similar to CIP, with the same mechanism observed when $\mathrm{pH}$ was 6-9.

\subsection{Plausible interaction mechanism between HA and SMZ, CIP}

Detailed information regarding elemental composition is listed in Table 8. The original HA has a relatively higher carbon content $(44.41 \%)$, followed by oxygen content $(28.6 \%)$, indicating that HA contains many oxygen functional groups. Notably, the carbon content of SMZ-adsorbed HA, CIP-adsorbed HA (CIP-HA) and SMZ + CIP-adsorbed HA (SMZ-HA) is higher than that of the original HA, contrary to the oxygen and hydrogen contents. In addition, the increase in the carbon content of SMZ + CIP-adsorbed HA is lower than those of SMZadsorbed HA and CIP-adsorbed HA, whereas the decrease in oxygen and hydrogen contents of SMZ + CIP-adsorbed HA is lower than those of SMZ-adsorbed HA and CIP-adsorbed HA. This phenomenon indicates that the adsorption rate of CIP and SMZ on humic acid might decrease due to a coexistence system.

Fig. 9 shows the infrared spectra of HA, CIP-HA and SMZ-HA, namely, the stretching vibration of $\mathrm{O}-\mathrm{H}$ at 3382, 3362 and $3390 \mathrm{~cm}^{-1}$. The bands at $2931 \mathrm{~cm}^{-1}$ and $1704 \mathrm{~cm}^{-1}$ can be assigned to $\mathrm{C}-\mathrm{H}$ and $\mathrm{C}=\mathrm{O}$ stretching vibrations, respectively. The band at $1610 \mathrm{~cm}^{-1}$ could be $\mathrm{C}=\mathrm{C}$ or $\mathrm{C}=\mathrm{O}$ stretching vibration on aromatic nuclei. The band at $1467 \mathrm{~cm}^{-1}$ could be the unsaturated $\mathrm{C}-\mathrm{H}$ bending vibration. The bands at $914 \mathrm{~cm}^{-1}$ and $757 \mathrm{~cm}^{-1}$ were assigned to the carboxylic acid $\mathrm{O}-\mathrm{H}$ and arene $\mathrm{C}-\mathrm{H}$ external bending vibrations, respectively. The band at $617 \mathrm{~cm}^{-1}$ could be external bending vibration formed by alcoholic hydroxyls. There is a significant adsorption peak at $1118 \mathrm{~cm}^{-1}$ that may correspond to the strong adsorption peak 
Table 8 Characterization of original HA, SMZ-adsorbed HA, CIP-adsorbed HA and SMZ + CIP-adsorbed HA

\begin{tabular}{llllll}
\hline & & Original HA & SMZ-adsorbed HA & CIP-adsorbed HA & SMZ + CIP-adsorbed HA \\
\hline Elemental analysis (atom based) (\%) & $\mathrm{C}$ & 44.41 & 52.78 & 53.01 & 52.13 \\
& $\mathrm{H}$ & 3.92 & 3.49 & 3.50 & 3.88 \\
& $\mathrm{O}$ & 28.60 & 22.12 & 22.01 & 22.48 \\
& $\mathrm{~N}$ & 1.19 & 1.53 & 1.49 & 1.60 \\
$A_{\text {surf }}\left(\mathrm{m}^{2} \mathrm{~g}^{-1}\right)$ & & $39.40 \mathrm{~m}^{2} \mathrm{~g}^{-1}$ & - & - & - \\
Zeta $/ \mathrm{MV}$ & & -6.05 & - & - & -
\end{tabular}

of aliphatic ethers. A pair of bands at $1035 \mathrm{~cm}^{-1}$ and $1033 \mathrm{~cm}^{-1}$ were assigned to the strong-polarity $\mathrm{C}-\mathrm{O}$ stretching vibrations. The band at $1257 \mathrm{~cm}^{-1}$ was assigned to $\mathrm{C}=\mathrm{O}$ or $\mathrm{O}-\mathrm{H}$ stretching vibration. The spectra of HA, CIP-HA and SMZ-HA were similar. However, the intensity of the characteristic peak of HA after coating with CIP and SMZ changed obviously, and a red shift occurred. At 3390, 2931, 1704 and $1118 \mathrm{~cm}^{-1}$, the intensity of the absorption peak was obviously weakened, indicating that the chemical adsorption of CIP and SMZ on humic acid mainly occurred on $\mathrm{O}-\mathrm{H}, \mathrm{C}-\mathrm{H}$ and $\mathrm{C}=\mathrm{O}$ bonds, and the intensity change for the absorption peak of CIP-HA was higher than that for SMZ-HA.

As a complex of the organic polymer class, humic acid contains various chemically reactive functional groups, such as carboxyl and hydroxyl functional groups, which cause complex interactions of HA with antibiotics. As seen in Fig. 9, the shifts of $\mathrm{O}-\mathrm{H}\left(3390 \mathrm{~cm}^{-1}\right)$ and $\mathrm{C}-\mathrm{O}\left(1118 \mathrm{~cm}^{-1}\right)$ were indicative of hydrogen bonding and hydrophobic interactions between HA and CIP or SMZ (Fig. 10). The mechanisms likely include the hydrogen bonding of aromatic carboxyl or hydroxyl groups on HA with $\mathrm{O}$ atoms in the carbonyl group of CIP, which was confirmed by $^{20}$ according to molecular dynamics (MD). In addition, the aromatic carboxyl group and ortho - $\mathrm{OH}$ group on $\mathrm{HA}$ interacts with the $\mathrm{O}$ atom of two adjacent carbonyl groups on CIP. Therefore, hydrogen bonds could be the main adsorption pathway for CIP on HA. ${ }^{19,20}$ Plausible mechanisms of SMZ on HA could be the synergistic effects of hydrogen-bonding and hydrophobic interaction. The amide of SMZ in solution could

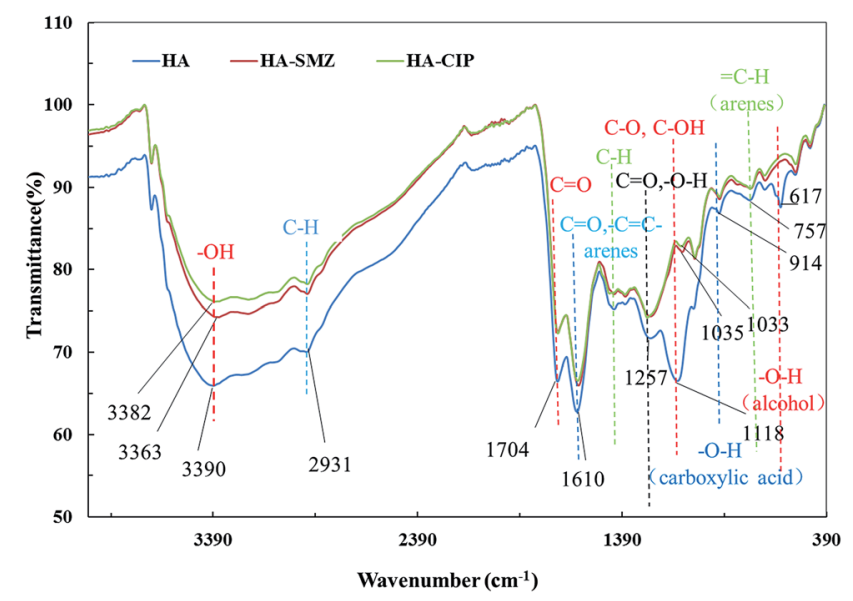

Fig. 9 FTIR spectra of HA, HA-SMZ and HA-CIP. effectively interact with hydroxyl via hydrogen bonding. In addition, the oxazole ring of electron deficiency was in parallel contact with the benzene ring in a face-to-face orientation, leading to the effective adsorption of SMZ on HA via hydrophobic interaction. Fig. 11 showed that the surface structure of HA before and after adsorption showed significant changes, indicating a strong interaction between some functional groups of HA and CIP or SMZ. The variable degree of HA-CIP was higher than that of HA-SMZ, consistent with the infrared spectra. Therefore, hydrogen bonds could be the most important adsorption pathway for CIP and SMZ on HA.

The absolute value of the free energy $(\Delta G)$ of CIP and SMZ was 2-29 kJ mol${ }^{-1}$, indicating that dipole moment force, electrostatic interactions, hydrophobic interaction and ion exchange played subsidiary roles that could also affect the adsorption of CIP and SMZ on HA. In addition, the electrostatic interaction significantly depended on $\mathrm{pH}$ in solution. When the pH of CIP and SMZ was below 5.9 and 1.6, the negative charge of

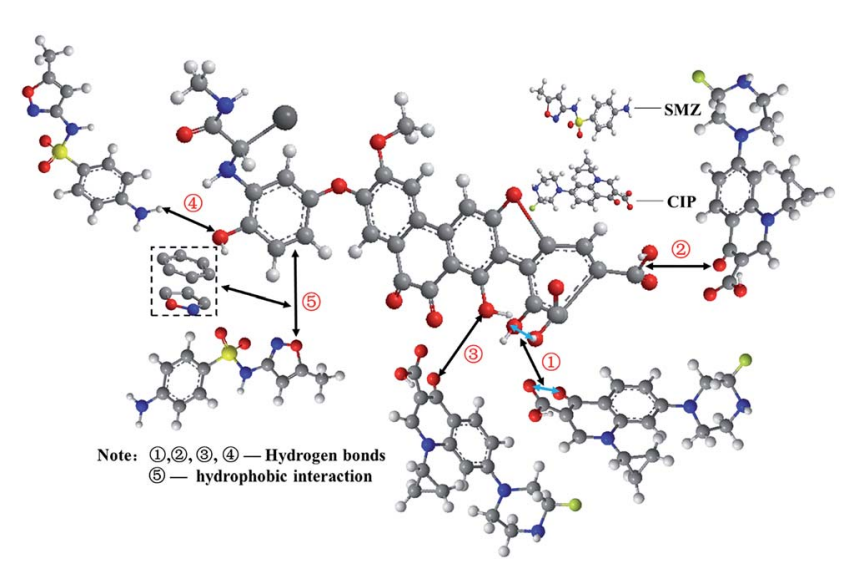

Fig. 10 Plausible interaction mechanism between HA and SMZ, CIP.

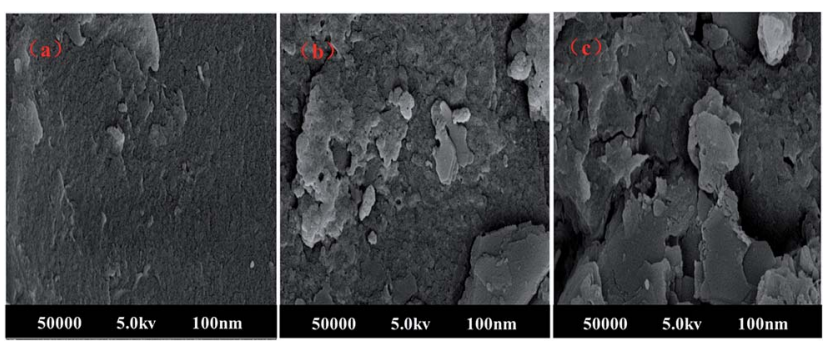

Fig. 11 The SEM images of (a) HA, (b) HA-SMZ and (c) HA-CIP. 
the acidic oxygen functional groups showed a strong electrostatic interaction between the cationic centres $\left(-\mathrm{NH}_{3}{ }^{+}\right)$of CIP and SMZ. Generally, CIP and SMZ exist as negative ions and neutral particles at neutral $\mathrm{pH}$. Thus, the electrostatic interaction among CIP, SMZ and HA is very weak in the 6.5-7.2 $\mathrm{pH}$ range used in this study.

\section{Conclusion}

The adsorption of CIP and SMZ on HA included the fastadsorption stage first and the slow-adsorption stage afterwards. The fast-adsorption stage could be fitted by the intraparticle diffusion model, and the entire adsorption process of CIP and SMZ on HA follows a pseudo-second-order kinetic equation. The adsorption efficiencies of HA to CIP were higher than those of SMZ. The adsorption isotherms of CIP and SMZ on HA were consistent with the Freundlich equation model. The adsorption mechanism of CIP and SMZ on HA could occur via hydrogen bonds. The effects of temperature and $\mathrm{pH}$ on the adsorption of CIP and SMZ on HA were significant compared to ionic strength. In addition, the competitive strength of CIP to SMZ was higher than that for SMZ to CIP in the coexistence system. The presence of HA in the environment could reduce the migration ability and environmental risk of CIP and SMZ. In addition, the adsorption of antibiotics on HA was influenced by many factors, and further study is needed to explore the specific mechanisms and assess the environmental risks and to guide the prevention and treatment of antibiotics.

\section{Conflicts of interest}

There are no conflicts to declare.

\section{Acknowledgements}

This work was financially supported by the Ministry of Science and Technology of China (Grant No. 2015FY110900).

\section{References}

1 R. Ma, B. Wang, S. Lu, et al., Characterization of pharmaceutically active compounds in Dongting Lake, China: occurrence, chiral profiling and environmental risk, Sci. Total Environ., 2016, 557, 268-275.

2 A. Harms, E. Maisonneuve and K. Gerdes, Mechanisms of bacterial persistence during stress and antibiotic exposure, Science, 2016, 354(6318), aaf4268.

3 F. F. Reinthaler, J. Posch, G. Feierl, et al., Antibiotic resistance of E. coli in sewage and sludge, Water Res., 2003, 37(8), 1685-1690.

4 C. Yan, Y. Yang, J. Zhou, et al., Antibiotics in the surface water of the Yangtze Estuary: occurrence, distribution and risk assessment, Environ. Pollut., 2013, 175, 22-29.

5 J. Xu, Y. Zhang, C. Zhou, et al., Distribution, sources and composition of antibiotics in sediment, overlying water and pore water from Taihu Lake, China, Sci. Total Environ., 2014, 497, 267-273.
6 J. Tang, T. Shi, X. Wu, et al., The occurrence and distribution of antibiotics in Lake Chaohu, China: seasonal variation, potential source and risk assessment, Chemosphere, 2015, 122, 154-161.

7 K. M. Shea, Antibiotic resistance: What is the impact of agricultural uses of antibiotics on children's health, Pediatrics, 2003, 112(1), 253-258.

8 Y. Luo, L. Xu, M. Rysz, et al., Occurrence and transport of tetracycline, sulfonamide, quinolone, and macrolide antibiotics in the Haihe River Basin, China, Environ. Sci. Technol., 2011, 45(5), 1827-1833.

9 P. Boundj and N. Voulvoulis, Pharmaceuticals in the Aquatic Environment: A Comparison of risk Assessment Strategies, Chemosphere, 2004, 56(11), 1143-1155.

10 D. Prabhakaran, P. Sukul, M. Lamshöft, et al., Photolysis of difloxacin and sarafloxacin in aqueous systems, Chemosphere, 2009, 77(6), 739-746.

11 C. C. Ryan, D. T. Tan and W. A. Arnold, Direct and indirect photolysis of sulfamethoxazole and trimethoprim in wastewater treatment plant effluent, Water Res., 2011, 45(3), 1280-1286.

12 J. Hou, B. Pan, X. Niu, et al., Sulfamethoxazole sorption by sediment fractions in comparison to pyrene and bisphenol A, Environ. Pollut., 2010, 158(9), 2826-2832.

$13 \mathrm{~K}$. Kümmerer, Antibiotics in the aquatic environment a review - part I, Chemosphere, 2009, 75(4), 417-434.

14 G. Zhang, H. Liu, J. Qu, et al., Arsenate uptake and arsenite simultaneous sorption and oxidation by $\mathrm{Fe}-\mathrm{Mn}$ binary oxides: Influence of $\mathrm{Mn} / \mathrm{Fe}$ ratio, $\mathrm{pH}, \mathrm{Ca}^{2+}$, and humic acid, J. Colloid Interface Sci., 2012, 366(1), 141-146.

15 J. J. Pignatello, Dynamic interactions of natural organic matter and organic compounds, J. Soils Sediments, 2012, 12(8), 1241-1256.

16 F. Lian, B. Sun, X. Chen, et al., Effect of humic acid (HA) on sulfonamide sorption by biochars, Environ. Pollut., 2015, 204, 306-312.

17 E. Čadková, M. Komárek, R. Kaliszová, et al., Sorption of tebuconazole onto selected soil minerals and humic acids, J. Environ. Sci. Health, Part B, 2012, 47(4), 336-342.

18 X. Guo, J. Ge, C. Yang, et al., Sorption behavior of tylosin and sulfamethazine on humic acid: kinetic and thermodynamic studies, RSC Adv., 2015, 5(72), 58865-58872.

19 L. Aristilde and G. Sposito, Complexes of the antimicrobial ciprofloxacin with soil, peat, and aquatic humic substances, Environ. Toxicol. Chem., 2013, 32(7), 1467-1478.

20 L. Aristilde and G. Sposito, Binding of ciprofloxacin by humic substances: a molecular dynamics study, Environ. Toxicol. Chem., 2010, 29(1), 90-98.

21 M. Borisover and E. R. Graber, Hydration of natural organic matter: effect on sorption of organic compounds by humin and humic acid fractions $v s$. original peat material, Environ. Sci. Technol., 2004, 38(15), 4120-4129.

22 L. Aristilde and G. Sposito, Molecular modeling of metal complexation by a fluoroquinolone antibiotic, Environ. Toxicol. Chem., 2008, 27(11), 2304-2310. 
23 W. Yan, S. Hu and C. Jing, Enrofloxacin sorption on smectite clays: effects of $\mathrm{pH}$, cations, and humic acid, J. Colloid Interface Sci., 2012, 372(1), 141-147.

24 Q. Zhang, L. Zhao, Y. Dong, et al., Sorption of norfloxacin onto humic acid extracted from weathered coal, J. Environ. Manage., 2012b, 102, 165-172.

25 V. Leone, P. Iovino, S. Salvestrini, et al., Sorption of non-ionic organic pollutants onto a humic acids-zeolitic tuff adduct: Thermodynamic aspects, Chemosphere, 2014, 95, 75-80.

26 M. Cleuvers, Mixture toxicity of the anti-inflammatory drugs diclofenac, ibuprofen, naproxen and acetylsalicylic acid, Ecotoxicol. Environ. Saf., 2004, 59(3), 309-315.

27 K. Yang, X. Wang, L. Zhu, et al., Competitive sorption of pyrene, phenanthrene, and naphthalene on multiwalled carbon nanotubes, Environ. Sci. Technol., 2006, 40(18), 5804-5810.

28 D. Zhang, B. Pan, H. Zhang, et al., Contribution of different sulfamethoxazole species to their overall adsorption on functionalized carbon nanotubes, Environ. Sci. Technol., 2010, 44(10), 3806-3811.

29 C. Wang, H. Li, S. Liao, et al., Coadsorption, desorption hysteresis and sorption thermodynamics of sulfamethoxazole and carbamazepine on graphene oxide and graphite, Carbon, 2013, 65, 243-251.

30 T. Farías, L. C. De Menorval, J. Zajac, et al., Benzalkonium chloride and sulfamethoxazole adsorption onto natural clinoptilolite: Effect of time, ionic strength, $\mathrm{pH}$ and temperature, J. Colloid Interface Sci., 2011, 363(2), 465-475.

$31 \mathrm{M}$. Brigante and M. Avena, Biotemplated synthesis of mesoporous silica for doxycycline removal. Effect of $\mathrm{pH}$, temperature, ionic strength and $\mathrm{Ca}^{2+}$ concentration on the adsorption behaviour, Microporous Mesoporous Mater., 2016, 225, 534-542.

32 G. Sposito, Effect of chloride ions on sodium-calcium and sodium-magnesium exchange on montmorillonite, Soil Sci. Soc. Am. J., 1991, 55(4), 965-967.

33 J. D. Filius, D. G. Lumsdon, J. C. L. Meeussen, et al., Adsorption of fulvic acid on goethite, Geochim. Cosmochim. Acta, 2000, 64(1), 51-60.

34 V. J. P. Vilar, C. M. S. Botelho and R. A. R. Boaventura, Influence of $\mathrm{pH}$, ionic strength and temperature on lead biosorption by Gelidium and agar extraction algal waste, Process Biochem., 2005, 40(10), 3267-3275.

35 Z. J. Wu, H. N. Liu and H. F. Zhang, Research progress on mechanisms about the effect of ionic strength on adsorption, Environ. Chem., 2010, 29, 997-1003.

36 I. Turku, T. Sainio and E. Paatero, Thermodynamics of tetracycline adsorption on silica, Environ. Chem. Lett., 2007, 5(4), 225-228.

37 J. M. Li, X. G. Meng, C. W. Hu, et al., Adsorption of phenol, pchlorophenol and $p$-nitrophenol onto functional chitosan, Bioresour. Technol., 2009, 100(3), 1168-1173.

38 C. Q. Huang, X. Zhang, D. C. Qiu, et al., Research on Adsorption of Methylene Blue onto the Mesoporous Silica Microspheres, Adv. Mater. Res., 2012, 557-559, 427-433.

39 X. Xiao, F. Tian, Y. Yan, et al., Adsorption behavior of phenanthrene onto coal-based activated carbon prepared by microwave activation, Korean J. Chem. Eng., 2015, 32(6), 1129-1136.

40 E. Çalışkan and S. Göktürk, Adsorption characteristics of sulfamethoxazole and metronidazole on activated carbon, Sep. Sci. Technol., 2010, 45(2), 244-255.

41 B. F. Chen, M. Wu, D. Zhang, et al., Research advance in sorption mechanisms of antibiotics in soil inorganic minerals, Chem. Ind. Eng. Prog., 2012, 31(01), 193-200.

42 Y. Liu, X. Liu, W. Dong, et al., Efficient Adsorption of Sulfamethazine onto Modified Activated Carbon: A Plausible Adsorption Mechanism, Sci. Rep., 2017, 7, 12437.

43 K. Wang, K. Z. Li, Y. Y. Zhou, et al., Adsorption characteristics of typical PPCPs onto river sediments and its influencing factors, J. Environ. Sci., 2015, 36(3), 847-854.

$44 \mathrm{H}$. Cui and S. P. Wang, Adsorption characteristics of ciprofloxacin in ustic cambosols, J. Environ. Sci., 2012, 33(8), 2895-2900.

45 S. A. C. Carabineiro, T. Thavorn-Amornsri, M. F. R. Pereira, et al., Comparison between activated carbon, carbon xerogel and carbon nanotubes for the adsorption of the antibiotic ciprofloxacin, Catal. Today, 2012, 186(1), 29-34.

46 S. Fukahori, T. Fujiwara, R. Ito, et al., pH-dependent adsorption of sulfa drugs on high silica zeolite: modeling and kinetic study, Desalination, 2011, 275(1), 237-242. 